\title{
Natural ECM-Bacterial Cellulose Wound Healing-Dubai Study
}

\author{
Safwat Mohd. El-Hoseny', Pierre Basmaji², Gabriel Molina de Olyveira ${ }^{3}$, \\ Ligia Maria Manzine Costa ${ }^{4}$, Abdulwahid M. Alwahedi', \\ José Domingos da Costa Oliveira², Gino Bruno Francozo ${ }^{2}$ \\ ${ }^{1}$ Al Qassimi Hospital, Sharjah, United Arab Emirates \\ Innovatec's-Biotechnology Research and Development, São Carlos, Brazil \\ ${ }^{3}$ Department of Physical Chemistry, UNESP, Araraquara, Brazil \\ ${ }^{4}$ Department of Chemistry, USP, FFCLRP, Ribeirão Preto, Brazil \\ Email: gabriel.ufabc@gmail.com,gmolyveira@yahoo.com.br
}

Received 31 July 2015; accepted 13 September 2015; published 16 September 2015

Copyright (C) 2015 by authors and Scientific Research Publishing Inc.

This work is licensed under the Creative Commons Attribution International License (CC BY). http://creativecommons.org/licenses/by/4.0/

(c) (i) Open Access

\begin{abstract}
Bacterial cellulose (BC) can be used in wide area of applied scientific, especially for tissue regeneration and regenerative medicine, lately, bacterial cellulose mats are used in the treatment of skin conditions such as burns and ulcers, because of the morphology of fibrous biopolymers serving as a support for cell proliferation, its pores allow gas exchange between the organism and the environment. Moreover, the nanostructure and morphological similarities with collagen make BC attractive for cell immobilization, cell support and Natural Extracellular Matrix (ECM) Scaffolds. In this scope, Natural ECM is the ideal biological scaffold since it contains all the components of the tissue. The development of mimicking biomaterials and hybrid biomaterial can further advance directed cellular differentiation without specific induction. The extracellular matrix (ECM) contains several signals that are received by cell surface receptors and contribute to cell adhesion and cell fate which control cellular activities such as proliferation, migration and differentiation. As such, regenerative medicine studies often rely on mimicking the natural ECM to promote the formation of new tissue by host cells, and characterization of natural ECM components is vital for the development of new biomimetic approaches. In this work, the bacterial cellulose fermentation process is modified by the addition of vegetal stem cell to the culture medium and natural materials before the bacteria are inoculated. In vivo behavior using natural ECM for regenerative medicine is presented.
\end{abstract}

\section{Keywords}

Bacterial Cellulose (Nanoskin), Natural Nanocomposites, Regenerative Medicine, Stem Cells 


\section{Introduction}

Patients with chronic wounds are treated successfully $(80 \%)$ by the district nurse or practice nurse staff [1].

After a certain time, often self-determined by the community nurse team, the non-healing patient is referred to a "wound care specialist" who will initially assess the wound care policy and patient records of how they have been treated to date. If the treatment was deemed to be poor or sub optimal, the wound care specialist will initially instigate a "gold standard" regime of advanced wound care therapy. If this therapy is successful, they will continue to healing with advanced wound care alone [2].

If the previous treatment undertaken was deemed to be good or gold standard care, the wound care specialist would assess the wound and recommend/use a series of advanced therapies which would be needed to promote the ultimate healing of the wound [3].

The improved understanding of the physiology of wounds and the processes involved in wound healing have resulted in a change of understanding as regards the wound environment and healing [3].

Previous non-healing wounds were assumed to have a deficiency in the epithelial cells, it was excepted a problem of Extra Cellular Matrix (ECM) which is the major issue in static non healing chronic wounds [4].

In this scope, Natural ECM is the ideal biological scaffold since it contains all the components of the tissue. Constructive remodeling can be performed using such natural ECM scaffolds and vegetal/animal stem cells, since the cells can be delivered to the site of infraction and then cells help wound healing process. The development of niche mimicking biomaterials and hybrid biomaterial can further advance directed differentiation without specific induction [5] [6].

The extracellular matrix (ECM) contains an abundant variety of signals that are received by cell surface receptors and contribute to cell adhesion and cell fate, via regulation of cellular activities such as proliferation, migration and differentiation. As such, regenerative medicine studies often rely on mimicking the natural ECM to promote the formation of new tissue by host cells, and characterization of natural ECM components is vital for the development of new biomimetic approaches [7] [8].

Bacterial cellulose (BC) is natural cellulose produced by bacterial synthesis, by biochemical steps and selfassembling of the secreted cellulose fibrils on the medium. Shaping of BC materials in the culture medium can be controlled by the type of cultivation that changes chain size, origin of strains which produces different proportions of crystalline phase of $\mathrm{BC}$ and the kind of bioreactor. $\mathrm{BC}$ hydrogel or $\mathrm{BC}$ in dry state is then obtained by methods, such as freeze-drying [9] [10]. The structural features of microbial cellulose, its properties and compatibility as a biomaterial for regenerative medicine can be changed by modifying its culture medium [11] or surface modification by physical [12] [13]; chemical methods [14] and genetic modifications [15] to obtain a biomaterial with less rejection when in contact to the body [16] [17].

Bacterial cellulose fibers mimics Collagen in creating an extra cellular matrix in the wound, which is neither originating from animals (e.g. SIS matrix) nor synthetic (man-made), and it therefore must be described as Artificial Biology. This artificial biological ECM replaces the body's own lost or damaged ECM and also stimulates the body to produce more of its own collagen, which supports the body's wound healing closure mechanism. Stimulating fibroblast production and subsequently TGF-b (Transforming growth factor beta) production will also be stimulated. Then granulation and epithelialization will start due to the presence of fibroblasts, endothelial cells are attracted to the wound producing growth factors, fibroblasts will release the body's own collagen and glycosaminoglycans. The combination of collagen and fibronectin forms the new ECM, ECM synthesis and new vessels, granulation tissue formation and epithelialization by keratinocyte migration, resulting in and increasing in the dermis volume and accelerating the healing. Besides, BC like Natural ECM also activates NK killer cells (same sized cells) T and B cells. The body then understands when to produce positive items (collagen etc.) and when to stop. Correcting wound modulation and kick starting correct cellular communication. The body then auto regulates the delivery of the necessary components necessary to promote wound repair and these fibers have high concentration of flavonoid compounds, diterpene, triterpene, lignans, phenylpropanoids and prenylated acetophenones which strengthen our immunity cells and improve our immune system [18] [19].

However, the success of the scaffold to be used in tissue engineering depends, in part, on the adhesion and growth of cells of interest on its surface. The surface chemistry of the material may define the cellular material and thus affect the adhesion, proliferation, migration and cell function [20]-[24].

In this work, novel studies of natural nanocomposites with Bacterial cellulose (Nanoskin ${ }^{\circledR}$ ) for functional materials are reported. In order to produce scaffolds with drug delivery ability, porous structure and better cell 
adhesion, fermentation changes in gel bacterial cellulose with chondroitin sulfate, hyaluronic acid and vegetal stem cells were performed and its in vivo cell behavior is presented.

\section{Materials and Methods}

\subsection{Materials}

The Bacterial cellulose (Nanoskin ${ }^{\circledR}$ ) raw material was provided from Innovatec's (São Carlos SP, Brazil). Chondroitin sulfate and hyaluronic acid sodium salt from Streptococcus equi (bacterial glycosaminoglycan polysaccharide) were purchased from Sigma Aldrich. Vegetal stem cells were obtained from Brazillian environment, Carapa guianensis and Copaifera langsdorffii Desf.

\subsection{Methods}

2.2.1. Synthesis of Bacterial Cellulose and Bacterial Cellulose/Chondroitin Sulfate/Hyaluronic Acid The acetic fermentation process was achieved by using glucose as a carbohydrate source. Results of this process are vinegar and a nanobiocellulose biomass. The modifying process is based on the addition of hyaluronic acid and chondroitin sulfate $(1 \% \mathrm{w} / \mathrm{w})$ to the culture medium before the bacteria is inoculated. Bacterial cellulose (BC) is produced by Gram-negative bacteria Gluconacetobacter xylinus, which can be obtained from the culture medium in the pure 3-D structure, consisting of an ultra fine network of cellulose nanofibers [19].

\subsubsection{Bionanocomposite Preparation}

In the present study, a novel biomaterial has been explored and different bacterial cellulose nanocomposites have been prepared; BC/chondroitin sulfate and hyaluronic acid. Samples were washed and its medium was changed with cells culture medium as illustrate in Figure 1.

\subsection{Vegetal Stem Cells}

The material of the plant of interest is collected and induced damage to causing the formation of scar tissue called callus. This tissue consists of totipotent cells, undifferentiated (stem cells) are collected and grown on agar plates to complete differentiation and generation of a homogeneous culture (2 - 10 days).

Cultures of these stem cells are grown in bioreactors and the batch is collected after all the sugar was metabolized. The cells are washed and homogenized to release secondary metabolites. Soluble metabolites in oil and water are collected and, if you need the isomalt-based spraying are performed.

\subsection{Characterization}

Scanning Electron Microscopy (SEM) images were performed on a PHILIPS XL30 FEG. The samples were covered with gold and silver paint for electrical contact and to perform the necessary images.

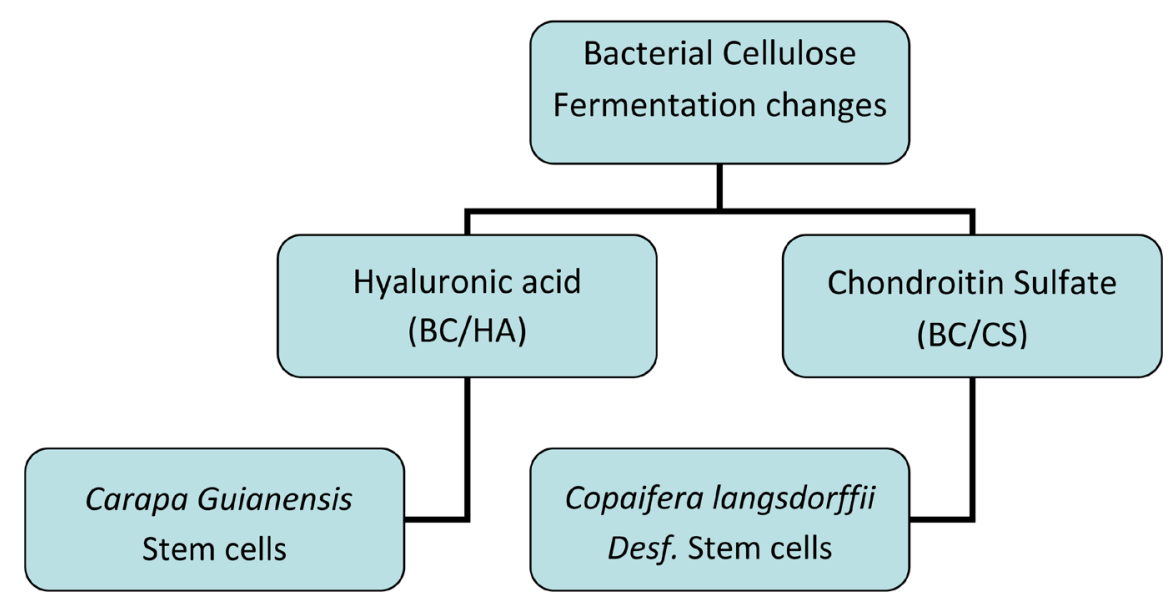

Figure 1. Materials and methods draft. 
Transmission infrared spectroscopy (FTIR, Perkin Elmer Spectrum 1000)-Influences of hyaluronic acid (HA) and chondroitin sulfate (CS) in bacterial cellulose were analyzed in the range between 250 and $4000 \mathrm{~cm}^{-1}$ and with $2 \mathrm{~cm}^{-1}$ resolution with samples.

In vivo analysis-Evaluation-Clinical study was done at Al Qassimi Hospital under supervision of Dr. Safwat Mohd. El-Hoseny. Evaluation model-patient with $3^{\text {rd }}$ degree burn by hot water; patient with car accident (rolled over).

\section{Results and Discussion}

\subsection{Morphological Behavior}

\subsubsection{Bacterial Cellulose Sample}

Bacterial cellulose mats were obtained by fermentation change and results showed bacterial cellulose bionanocomposites surface as illustrated in Figure 2.

\subsubsection{Hyaluronic Acid/Bacterial Cellulose Mats}

Hyaluronic acid/bacterial cellulose mats were modified with hyaluronic acid and results showed bacterial cellulose bionanocomposites surface as illustrated in Figure 3.

\subsubsection{Chondroitin Sulfate/Bacterial Cellulose Mats}

Chondroitin sulfate/bacterial cellulose mats were modified with chondroitin sulfate and results showed bacterial cellulose bionanocomposites surface as illustrated in Figure 4.

It can be observed that bacterial cellulose was successfully modified by changing the fermentation medium and sample with hyaluronic acid has little differences in surface morphology than tested others mainly because there is higher hydrogen bond between bacterial cellulose groups (hydroxyl) and hyaluronic acid (acetyl) which changes bacterial cellulose fibers formation and surface morphology.

\subsection{FTIR-Interaction between Bacterial Cellulose with Hyaluronic Acid and Chondroitin Sulfate}

Influences of hyaluronic acid (HA) and chondroitin sulfate (CS) in bacterial cellulose were analyzed in the range between 250 and $4000 \mathrm{~cm}^{-1}$ and with resolution of $2 \mathrm{~cm}^{-1}$ with FTIR analysis. The main features of the bacterial cellulose in infrared spectroscopy is: $3500 \mathrm{~cm}^{-1}$ : OH stretching, $2900 \mathrm{~cm}^{-1}$ : CH stretching of alkane and asymmetric $\mathrm{CH}_{2}$ stretching, $2700 \mathrm{~cm}^{-1}$ : $\mathrm{CH}_{2}$ symmetric stretching, $1640 \mathrm{~cm}^{-1}$ : OH deformation, $1400 \mathrm{~cm}^{-1}$ : $\mathrm{CH}_{2}$ deformation, $1370 \mathrm{~cm}^{-1}$ : $\mathrm{CH}_{3}$ deformation, $1340 \mathrm{~cm}^{-1}$ : OH deformation and $1320-1030 \mathrm{~cm}^{-1}$ : CO deformation [23]-[26].

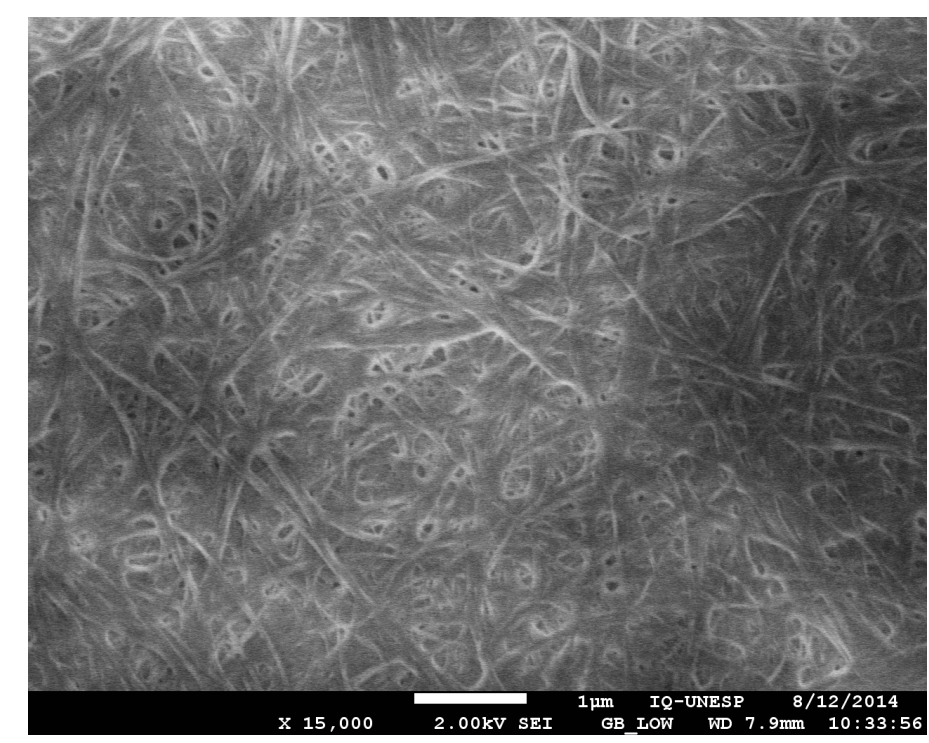

Figure 2. SEM images of bacterial cellulose mats. 


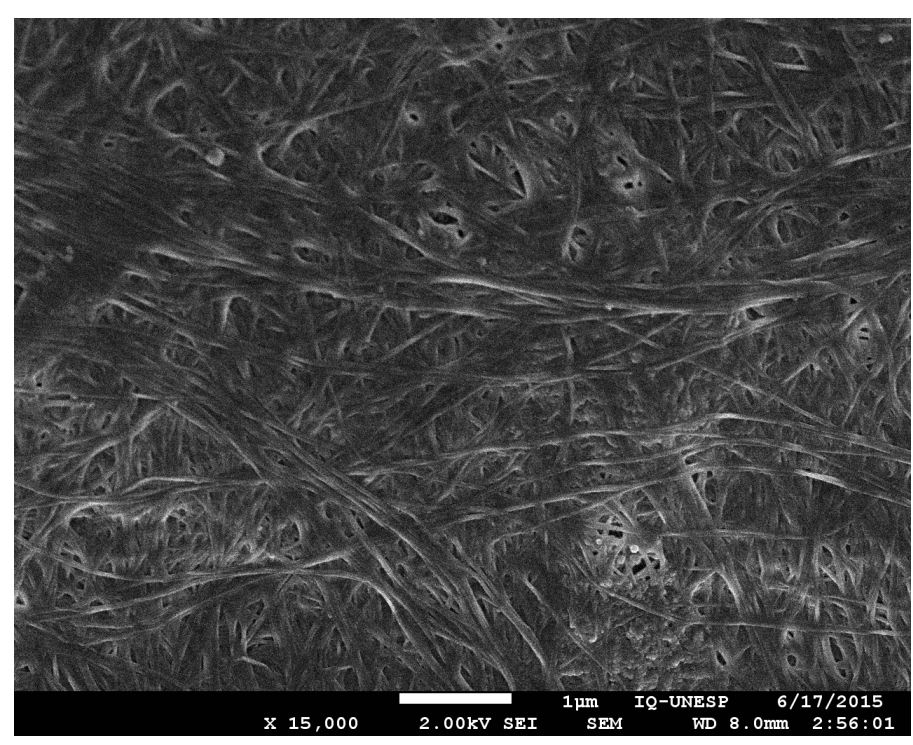

Figure 3. SEM images of bacterial cellulose/hyaluronic acid mats.

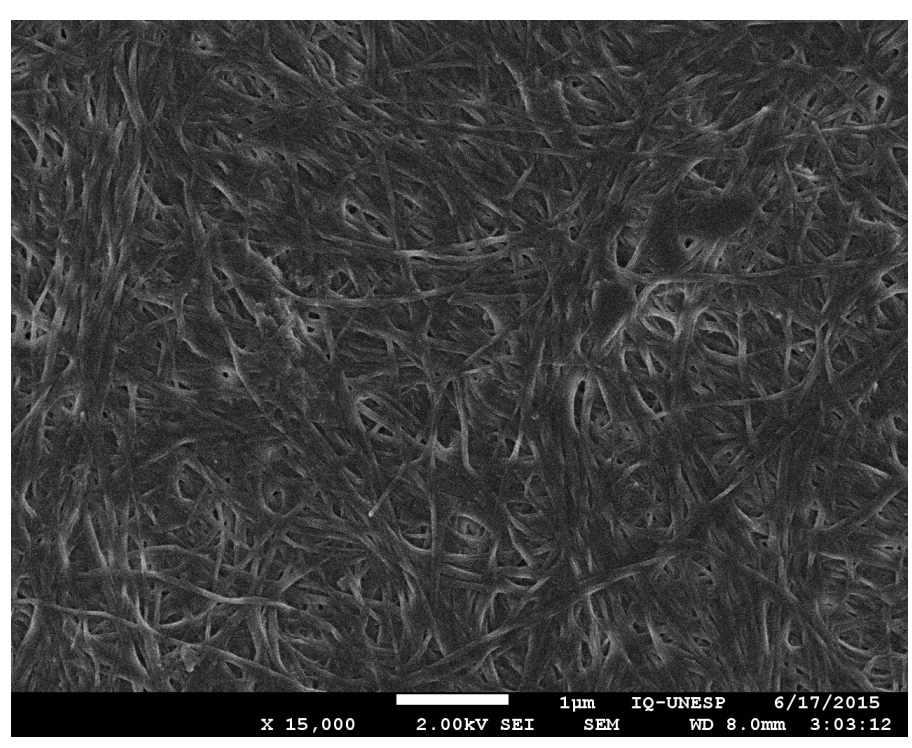

Figure 4. SEM images of bacterial cellulose/chondroitin sulfate mats.

In the case of FT-IR spectra of bacterial cellulose/chondroitin sulfate (BC/CS) nanocomposites, there were no shifts in the bands of carboxylate $1640 \mathrm{~cm}^{-1}$ and sulfate groups that appear at $1250 \mathrm{~cm}^{-1}$ and $1230 \mathrm{~cm}^{-1}$ in bacterial cellulose/chondroitin sulfate nanocomposites (Figure 5). However, it has exhibited broad overlapping bands at $1640 \mathrm{~cm}^{-1}$ (primary amide bond stretching) and $1564 \mathrm{~cm}^{-1}$ (aromatic $\mathrm{C}=\mathrm{C}$ stretching vibrations), as well as N-H bending vibrations at $1508 \mathrm{~cm}^{-1}$ [24]-[26]. Besides, it was assigned an increase of intensity absorption bands at $1250 \mathrm{~cm}^{-1}$ and $1230 \mathrm{~cm}^{-1}$ due to sulphate-related modes, corresponding to antisymmetric and symmetric stretching of the sulphate group, respectively. The intensity of the antisymmetric bridge oxygen stretching band at $1163 \mathrm{~cm}^{-1}$ was reduced after formation of BC/CS nanocomposite, indicating a change in the hydrogen-bonding of the bridge oxygen after the addition of chondroitin sulfate in the system. The visible spectral profile changes observed at $897 \mathrm{~cm}^{-1}$, corresponding to characteristic of $\beta$-anomers or $\beta$-linked glucose polymers, assigned as $\mathrm{C}-\mathrm{O}-\mathrm{C}$ stretching of the $\beta$ - $(1 \rightarrow 4)$-glycosidic linkage. This band becomes sharp and strong in the BC/CS nanocomposite. It can be explained from participation of the oxygen atom attached to C1 in this vibration and changes in the hydrogen bonding in cellulose [23]-[26]. Therefore, the results clearly show one possible interaction between bacterial cellulose and chondroitin sulfate, mainly by hydrogen interactions between 


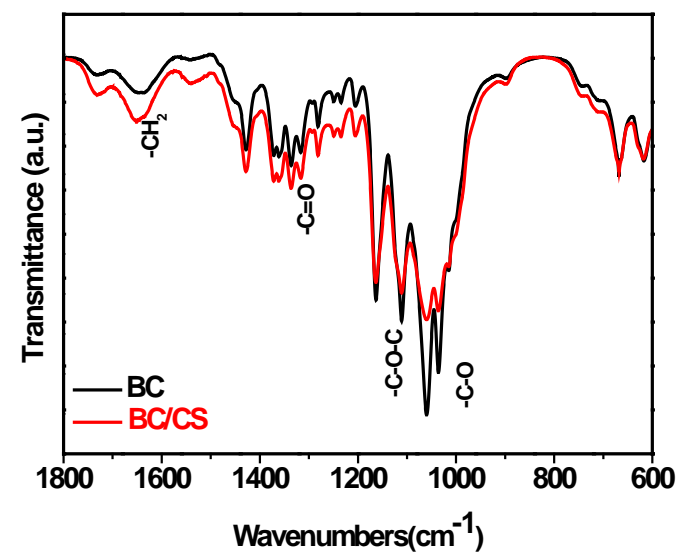

Figure 5. FTIR spectra of bacterial cellulose/chondroitin sulfate nanocomposites.

hydroxyl and carbonyl groups.

It can be observed similar OH stretching (at $2900 \mathrm{~cm}^{-1}$ ) in bacterial cellulose/hyaluronic acid nanocomposites (BC/HA), mainly because of the $\mathrm{NH}_{2}$ interaction with hydroxyl groups (Figure 6). Besides, it can be observed a shift from (H-O-H) absorption band at $1640 \mathrm{~cm}^{-1}$ of bacterial cellulose structures and amide I absorption from $\mathrm{HA}$ at $1620 \mathrm{~cm}^{-1}$, indicating an integrated HA/BC molecules. Another absorption peak was obtained in the range of $1490 \mathrm{~cm}^{-1}$ on both samples, which shows the presence of a carbonyl group in the bacterial cellulose together with bonds corresponding to those of glycoside, including C-O-C at $1162 \mathrm{~cm}^{-1}$ (as in the case of natural cellulose) [23]-[26]. These results clearly show one possible interaction between bacterial cellulose and hyaluronic acid, mainly by hydrogen interactions between hydroxyl and carbonyl groups.

\subsection{In Vivo Analysis}

Patient (M. A. A. A.) enters in Al Qassimi Hospital on 08/20/2013 under supervision of Dr. Safwat Mohd. El-Hoseny, diagnosed with 3rd degree burns by hot water. It was performed immediate intervention with antibiotics and clinical protocols for this disease. In 2013 September started treatment of thick slough and debridement. In October 2013, treatment with Bacterial cellulose membranes (Nanoskin $\left.{ }^{\circledR}\right)$.

After using the Bacterial cellulose material in alternate days, it can be observed an excellent recovery of the edge and bottom of the wound and wound area reduction (70\% extension) in 3 weeks as illustrated in Figure 7 (a-before and b-after). The aesthetic gain of the lesion was excellent. In November 2013, burns healing completely.

The simple application of dressing only required the association of saline, gauze and bandage, decrease patient stay and operating room use, resulting in a better cost-benefit.

Patient (Y. S. S. A.) enters in Al Qassimi Hospital on 10/07/2014 under supervision of Dr. Safwat Mohd. El-Hoseny, diagnosed with hand skin loss wound by car accident. In the beginning, there were deep full thickness skin loss and multiple thickness friction burns on hand and fingers. All wounds were cleaned with Betadine solution, then covered with flamazine cream dressing, patient still complain several pain at all times as illustrated in Figure 8(a). In 10/15/2014 started Bacterial cellulose (Nanoskin $®$ ) Dressing, all wounds gets better with (Nanoskin ${ }^{\circledR}$ ) dressing, dramatic changes was noted after application of (Nanoskin ${ }^{\circledR}$ ) dressing, patient rarely complain of pain. In 12/21/2014 completely healing using (Nanoskin®) dressing as illustrated in Figure 8(b).

\section{Conclusions}

Bacterial cellulose (Nanoskin ${ }^{\circledR}$ ) was successfully modified by changing the fermentation medium as shown by FTIR and SEM, which produced suitable scaffolds for use in surface morphology applications with promising cell viability/attachment.

Bacterial cellulose (BC) is used in the treatment of skin conditions such as burns and ulcers, because of the 


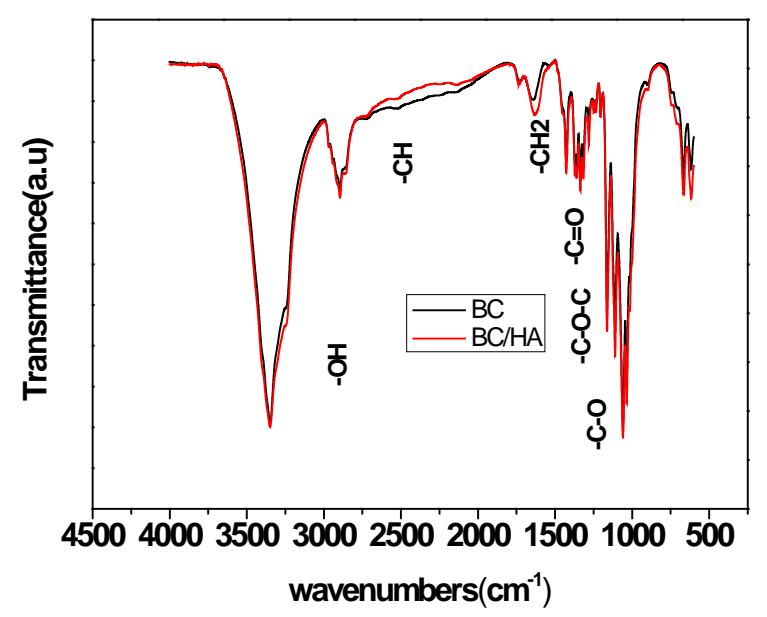

Figure 6. FTIR spectra of bacterial cellulose/hyaluronic acid nanocomposites.

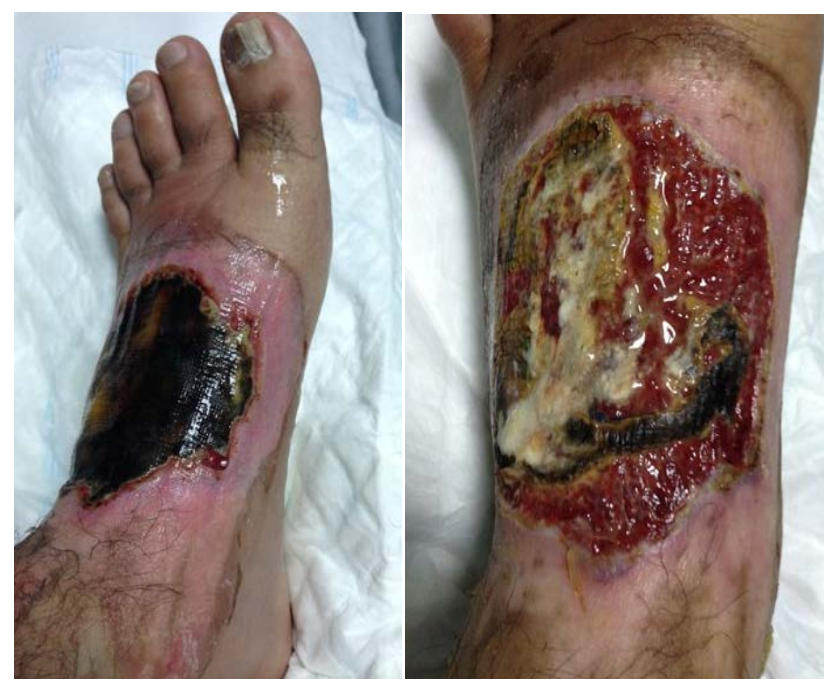

(a)

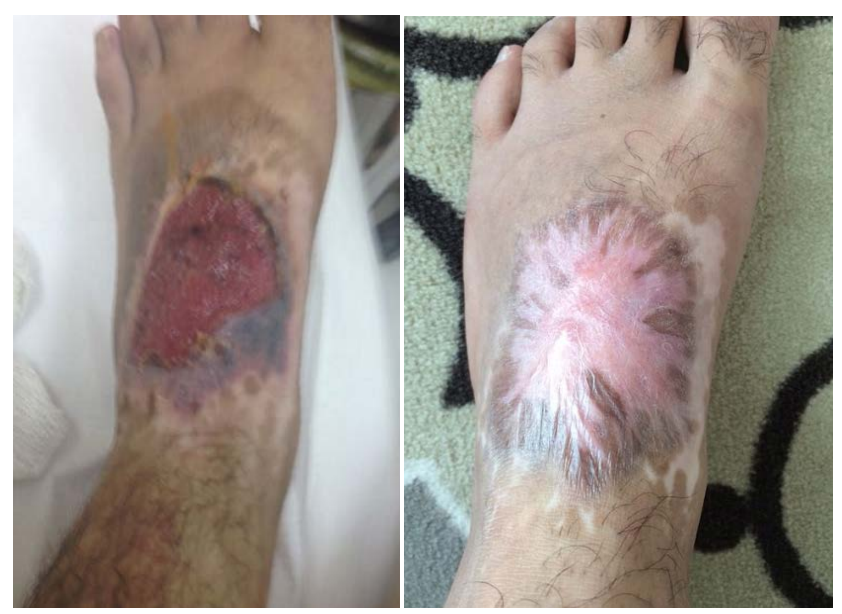

(b)

Figure 7. Wound healing evolution in 3 months and Bacterial cellulose $\left(\right.$ Nanoskin $\left.{ }^{\circledR}\right)$ impact use in biological wound dressing. 


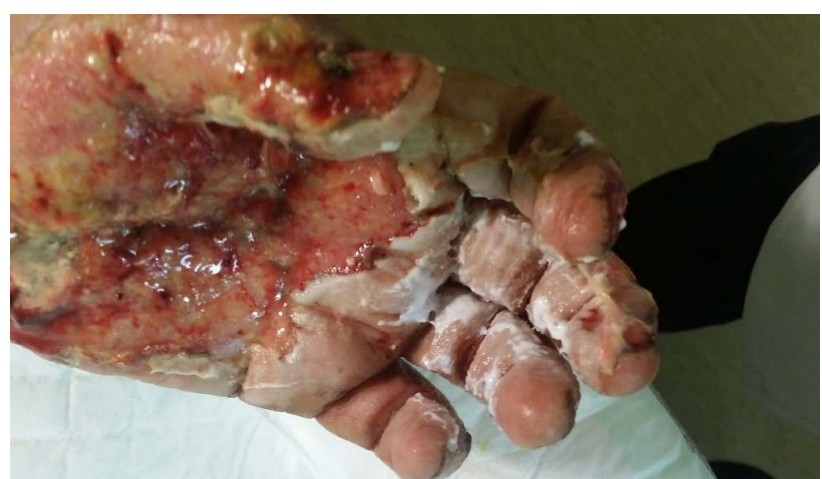

(a)
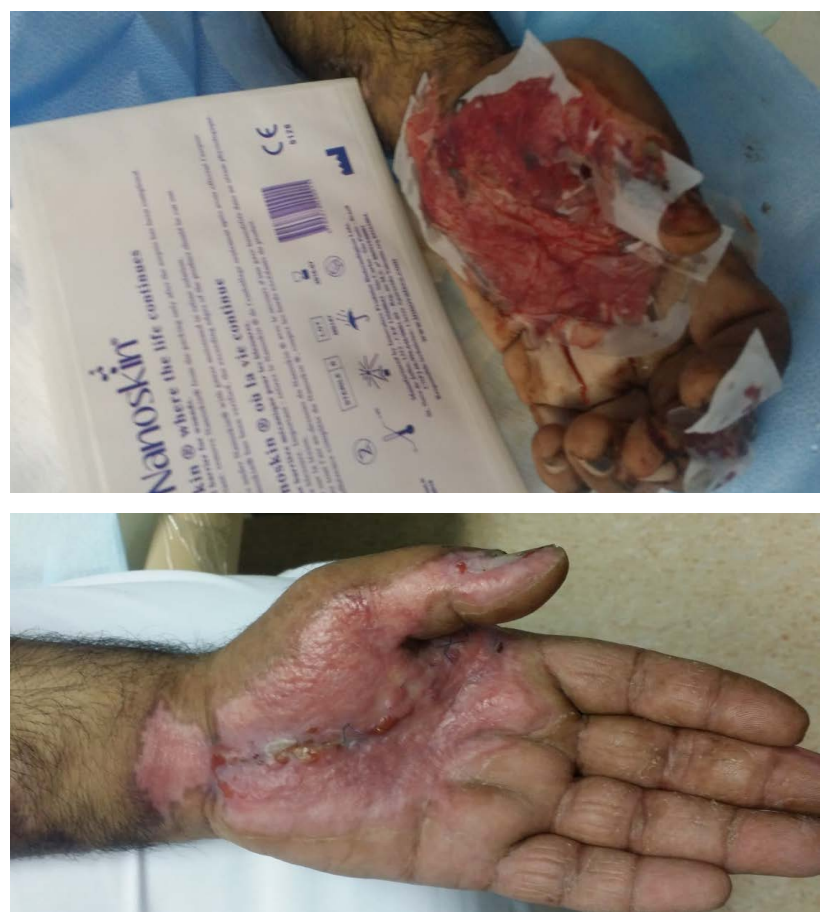

(b)

Figure 8. Wound healing evolution in 2 months and Bacterial cellulose impact use in biological wound dressing.

morphology of fibrous biopolymers serving as a support for cell proliferation, moreover, the nanostructure and morphological similarities with collagen make BC attractive for cell immobilization, cell support and Natural Extracellular Matrix (ECM) Scaffolds, then vegetal stem cells are natural choice in regenerative medicine.

In conclusion, Bacterial cellulose (Nanoskin ${ }^{\circledR}$ ) membrane applies to the protective cover and sutures, with or without exudate lesions, in unfavorable healing and with large areas until decubitus sores, its uses can be for all age people.

\section{References}

[1] Canavan, R., Connolly, V., Mcintosh, J., Airey, M. and Unwin, N. (2003) Geographic Variation in Lower Extremity Amputation Rates. Diabetic Foot, 6, 82-89.

[2] Vowden, K.R. and Vowden, P. (1996) Peripheral Arterial Disease. Journal of Wound Care, 5, 23-26.

[3] Van Gent,W.B., Wilschut, E.D. and Wittens, C. (2010) Management of Venous Ulcer Disease. BMJ, 341, Article ID: c6045. http://dx.doi.org/10.1136/bmj.c6045

[4] Rayner, R., Carville, K., Keaton, J., Prentice, J. and Santamaria, X.N. (2009) Leg Ulcers: Atypical Presentations and 
Associated Comorbidities. Wound Practice and Research, 17, 168-185.

[5] Rahman, G.A., Adigun, I.A. and Fadeyi, A. (2010) Epidemiology, Etiology, and Treatment of Chronic Leg Ulcer: Experience with Sixty Patients. Annals of African Medicine, 9, 1-4. http://dx.doi.org/10.4103/1596-3519.62615

[6] Faria, E., Blanes, L., Hochman, B., Filho, M.M. and Ferreira, L. (2011) Health-Related Quality of Life, Self-Esteem, and Functional Status of Patients with Leg Ulcers. Wounds, 23, 4-10.

[7] Siddiqui, A.R. and Bernstein, J.M. (2010) Chronic Wound Infection: Facts and Controversies. Clinics in Dermatology, 28, 519-526. http://dx.doi.org/10.1016/j.clindermatol.2010.03.009

[8] Han, A., Zenilman, J.M., Melendez, J.H., Shirtliff, M.E., Agostinho, A., James, G., Stewart, P.S., Mongodin, E.F., Rao, D., Rickard, A.H. and Lazarus, G.S. (2011) The Importance of a Multi-Faceted Approach to Characterizing the Microbial Flora of Chronic Wounds. Wound Repair and Regeneration, 19, 532-541. http://dx.doi.org/10.1111/j.1524-475X.2011.00720.x

[9] Costa, L.M.M., Olyveira, G.M., Basmaji, P., Valido, D.P., Góis, P.B.P., Júnior, R.L.A.C. and Filho, L.X. (2012) Novel Otoliths/Bacterial Cellulose Nanocomposites as a Potential Natural Product for Direct Dental Pulp Capping. Journal of Biomaterials and Tissue Engineering, 2, 48-53. http://dx.doi.org/10.1166/jbt.2012.1031

[10] Olyveira, G.M., Santos, M.L., Riccardi, C.S., Costa, L.M.M., Daltro, P.B., Basmaji, P., Daltro, G.C. and Guastaldi, A.C. (2015) Bacterial Cellulose Biocomposites for Periodontology Treatment. Advanced Science, Engineering and Medicine, 6, 1-6. http://dx.doi.org/10.1166/asem.2015.1641

[11] Costa, L.M.M., Olyveira, G.M., Basmaji, P. and Filho, L.X. (2011) Bacterial Cellulose towards Functional Green Composites Materials. Journal of Bionanoscience, 5, 167-172. http://dx.doi.org/10.1166/jbns.2011.1060

[12] Costa, L.M.M., Olyveira, G.M., Basmaji, P. and Filho, L.X. (2012) Bacterial Cellulose towards Functional Medical Materials. Journal of Biomaterials and Tissue Engineering, 2, 185-196. http://dx.doi.org/10.1166/jbt.2012.1044

[13] Olyveira, G.M., Costa, L.M.M. and Basmaji, P. (2013) Physically Modified Bacterial Cellulose as Alternative Routes for Transdermal Drug Delivery. Journal of Biomaterials and Tissue Engineering, 2, 1-6.

[14] Olyveira, G.M., Riccardi, C.S., Santos, M.L., Costa, L.M.M., Daltro, P.B., Basmaji, P., Daltro, G.C. and Guastaldi, A.C. (2014) Bacterial Cellulose Nanobiocomposites for Periodontal Disease. Journal of Bionanoscience, 8, $319,324$. http://dx.doi.org/10.1166/jbns.2014.1241

[15] Gois, P.B.P., Olyveira, G.M., Costa, L.M.M., Chianca, C.F., Fraga, I.I.S., Basmaji, P., Cordoba, C.V. and Filho, L.X. (2013) Influence of Symbioses Culture between Microorganisms/Yeast Strain on Cellulose Synthesis. International Review of Biophysical Chemistry, 3, 48-54.

[16] Filho, L.X., OLyveira, G.M., Costa, L.M.M. and Basmaji, P. (2013) Novel Electrospun Nanotholits/PHB Scaffolds for Bone Tissue Regeneration. Journal of Nanoscience and Nanotechnology, 13, 1-5. http://dx.doi.org/10.1166/jnn.2013.7191

[17] Olyveira, G.M., Costa, L.M.M., Basmaji, P. and Filho, L.X. (2011) Bacterial Nanocellulose for Medicine Regenerative. Journal of Nanotechnology in Engineering and Medicine, 2, 34001-34009. http://dx.doi.org/10.1115/1.4004181

[18] Olyveira, G.M., Santos, M.L., Daltro, P.B., Basmaji, P., Daltro, G.C. and Guastaldi, A.C. (2014) Bacterial Cellulose/Chondroitin Sulfate for Dental Materials Scaffolds. Journal of Biomaterials and Tissue Engineering, 4, 1-5. http://dx.doi.org/10.1166/jbt.2014.1155

[19] Olyveira, G.M., Santos, M.L., Costa, L.M.M., Daltro, P.B., Basmaji, P., Daltro, G.C. and Guastaldi, A.C. (2014) Bacterial Cellulose Nanobiocomposites for Dental Materials Scaffolds. Journal of Biomaterials and Tissue Engineering, 4, 536-542. http://dx.doi.org/10.1166/jbt.2014.1202

[20] Olyveira, G.M., Santos, M.L., Costa, L.M.M., Daltro, P.B., Basmaji, P., Daltro, G.C. and Guastaldi, A.C. (2014) Bacterial Biocomposites for Guided Tissue Regeneration. Science of Advanced Materials, 6, 1-6. http://dx.doi.org/10.1166/sam.2014.1985

[21] Olyveira, G.M., Santos, M.L., Costa, L.M.M., Daltro, P.B., Basmaji, P., Daltro, G.C. and Guastaldi, A.C. (2015) Physically Modified Bacterial Cellulose Biocomposites for Guided Tissue Regeneration. Science of Advanced Materials, 7, $1-8$.

[22] Olyveira, G.M., Santos, M.L., Costa, L.M.M., Riccardi, C.S., Daltro, P.B., Basmaji, P., Daltro, G.C. and Guastaldi, A.C. (2015) Physically Modified Bacterial Cellulose Biocomposites for Dental Materials Scaffolds. Materials Focus, 4, 1-7. http://dx.doi.org/10.1166/mat.2015.1224

[23] Olyveira, G.M., Acasigua, G.A.X., Costa, L.M.M., Scher, C.R., Filho, L.X., Pranke, P.H.L. and Basmaji, P. (2013) Human Dental Pulp Stem Cell Behavior Using Natural Nanotolith/Bacterial Cellulose Scaffolds for Regenerative Medicine. Journal of Biomedical Nanotechnology, 9, 1-8. http://dx.doi.org/10.1166/jbn.2013.1620

[24] Acasigua, G.A.X.m Olyveira, G.M., Costa, L.M.M., Braghirolli, D.A., Guastaldi, A.C., Pranke, P. and Basmaji, P. (2014) Novel Natural Bacterial Cellulose Nanocomposites as Potential Biomaterial for Stem Cell Therapy. Current Stem Cell Research and Therapy, 9, 117-123. http://dx.doi.org/10.2174/1574888X08666131124135654 
[25] Salmen, L., Akerholm, M. and Hinterstoisser, B. (2005) Two-Dimensional Fourier Transform Infrared Spectroscopy Applied to Cellulose and Paper. In: Dumitriu, S., Ed., Polysaccharides: Structural Diversity and Functional Versatility, 2nd Edition, Marcel Dekker, New York, 159-187.

[26] Kondo, T. (1998) Hydrogen Bonds in Cellulose and Cellulose Derivatives. In: Dumitriu, S., Ed., Polysaccharides: Structural Diversity and Functional Versatility, Marcel Dekker, Inc., New York, 131-172. 